\title{
Mechanical Response of Typical Cement Concrete Pavements under Impact Loading
}

\author{
Ding Fei, ${ }^{1}$ Yin Yan, ${ }^{2}$ Cai Liangcai, ${ }^{1}$ Tang Yaohong, ${ }^{3}$ and Wang Xuancang ${ }^{2}$ \\ ${ }^{1}$ Aeronautics and Astronautics Engineering College, Air Force Engineering University, Xian, Shaanxi 710038, China \\ ${ }^{2}$ School of Highway, Chang'an University, Xi'an, Shaanxi 710064, China \\ ${ }^{3}$ Shanghai Municipal \& Traffic Design Institute Co., Ltd., Shanghai 200030, China
}

Correspondence should be addressed to Ding Fei; 240003582@qq.com

Received 29 September 2016; Accepted 12 December 2016; Published 16 January 2017

Academic Editor: Francesco Pesavento

Copyright (C) 2017 Ding Fei et al. This is an open access article distributed under the Creative Commons Attribution License, which permits unrestricted use, distribution, and reproduction in any medium, provided the original work is properly cited.

\begin{abstract}
In order to study the mechanical response of cement concrete pavements under impact loading, four types of typical cement concrete pavement structures are investigated experimentally and numerically under an impact load. Full-scale three-dimensional pavement slots are tested under an impact load and are monitored for the mechanical characteristics including the deflection of the pavement surface layer, the strain distribution at the bottom of the slab, and the plastic damage and cracking under the dynamic impact load. Numerical analysis is performed by developing a three-dimensional finite element model and by utilizing a cement concrete damage model. The results show that the calculation results based on the cement concrete damage model are in reasonable agreement with the experimental results based on the three-dimensional test slot experiment. The peak values of stress and strain as monitored by the sensors are analyzed and compared with the numerical results, indicating that the errors of numerical results from the proposed model are mostly within $10 \%$. The rationality of the finite element model is verified, and the model is expected to be a suitable reference for the analysis and design of cement concrete pavements.
\end{abstract}

\section{Introduction}

At present, design specifications of a cement concrete pavement adopt three kinds of theoretical models, namely, elastic foundation of a single slab, elastic foundation of a double slab, and composite slab models [1-5]. These parametric calculation models incorporate idealized material properties for concrete materials that are based on their performance under heavy loading traffic [6-9]. Therefore, the calculation method provided in the existing design specifications of a cement concrete pavement is not applicable for the mechanical characteristics of concrete materials under an impact load.

From the 1950s, researchers have analyzed the stressstrain characteristics of elastic pavement materials under dynamic loads. For instance, Eason et al. (Year) used the Fourier transform in perfectly elastic physical equations and general equations of motion to investigate road boundary conditions and to solve theoretical formula and then to obtain expressions for pavement structures' displacement and stress and strain under moving loads. However, there is still dearth of study on the mechanical response of a cement concrete pavement structure under an impact load.

In this paper, a variety of typical cement concrete pavement structures are numerically and experimentally analyzed under an impact load. The numerical analysis was performed by implementing cement concrete damage model in a threedimensional finite element method (FEM). The experimental investigation involved a full-scale three-dimensional slot test. The mechanical characteristics including the deflection of concrete pavement surface layer, the strain distribution at the bottom of slab, and the plastic damage cracking under dynamic impact load are studied.

\section{The Full-Scale Loading Slot Experiment}

2.1. Impact Load Characteristics. In order to explore the dynamic response law of the concrete pavement structure under an impact load and over load, an impact load was designed as shown in Figure 1 and the load was applied to the pavement structure by a dynamic loading device. The acting 


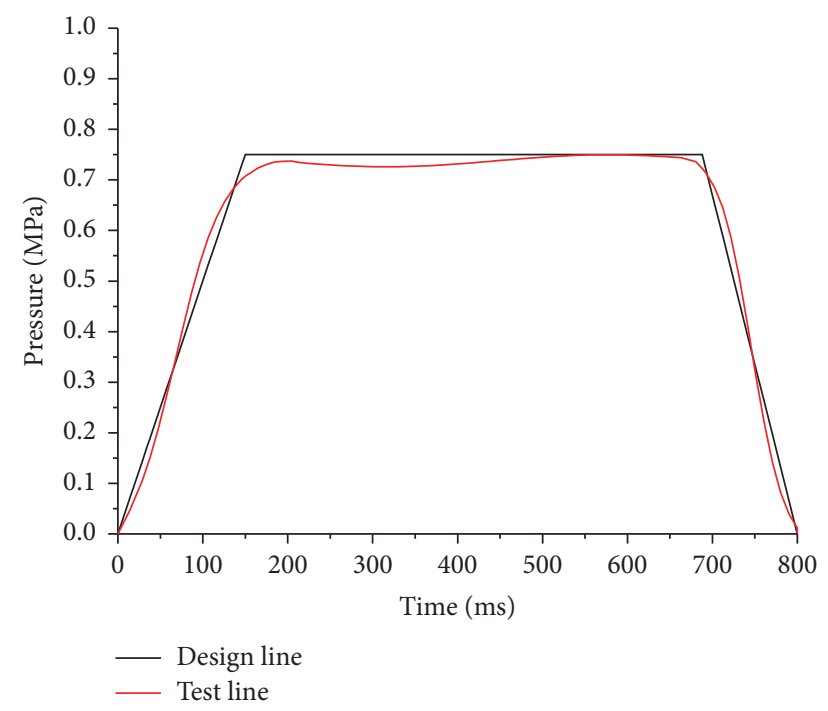

FIGURE 1: Schematic diagram of the impact load.

face of the loading device comprised a circular area with the diameter of $2 \mathrm{~m}$ at the center of concrete surface. The impact load was imposed on it with the maximum uniform pressure of 0.5 MPa. As shown in Figure 1, the load pressure reached its peak at $200 \mathrm{~ms}$, stayed constant from 200 to $660 \mathrm{~ms}$, and gradually declined after $660 \mathrm{~ms}$. The two time points, namely, $200 \mathrm{~ms}$ and $660 \mathrm{~ms}$, are the key time points in this study.

2.2. Typical Pavement Model. After extensively reviewing cement concrete pavements of six regions in China, four kinds of typical pavement structures, as summarized in Table 1, were selected for the analysis in this study.

2.3. Experimental Program. In order to study the mechanical response law of cement concrete pavement under impact load, this study performed three-dimensional full-scale loading test slot experiment on the four cement concrete pavement structures as shown in Table 1. Mechanical response of the pavement structures under static heavy load and transient impact load was investigated by measuring the internal stresses and strains of the pavement structures and their surface displacements. Failure modes under the impact load were also observed for the pavement structures. The experimental data from this test were utilized in the subsequent analysis of dynamic response characteristics and the finite element analysis of road structures.

The experimental set-up is shown in Figure 2. The loading device in this experiment applied a uniform circular load over a pavement area of $2 \mathrm{~m}$ diameter. The loading point was determined as the center of the cement concrete pavement slab and a rubber base was used for loading. The loading points on the outriggers were determined relative to the position of the rubber base. Loading on the front and rear outriggers was realized by replacing the bearing slab.

2.3.1. Scheme for Burying Sensors. Under an impact load, the structural dynamic response of concrete pavement structures varies quickly, which requires sensors to have certain data

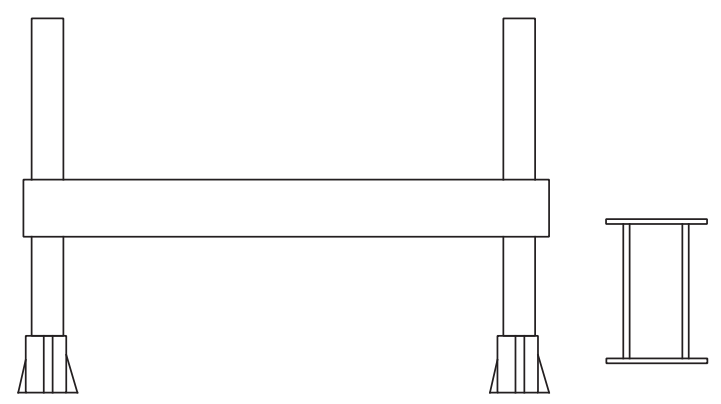

FIGURE 2: Schematic diagram of the reaction frame and II-shape beam used in loading the pavement slabs.

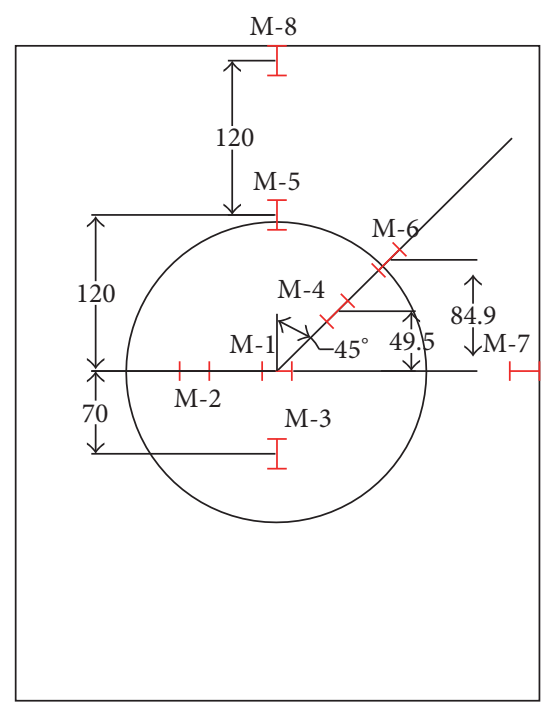

FIGURE 3: Layout of strain sensors on the concrete slab.

acquisition performances. In this three-dimensional test slot experiment, the method of combining multiple dynamic sensors and dynamic data acquisition was adopted. After rigorously reviewing the market availability, sensors were selected such that they have high dynamic frequency and stable performance, and at the same time they can be buried simply and conveniently inside the concrete pavement slabs $[14,15]$. The layout of dynamic strain sensors at the bottom of a concrete slab is shown in Figure 3, where M1, M2, and M7 were aligned horizontally; M3, M5, and M8 were aligned longitudinally; and M4 and M6 were aligned at an inclination angle of $45^{\circ}$ on the concrete lab. In order to better detect the change in compressive stress at different roadbed depths, the sensors were placed in four layers with varying depths as shown in Figure 4. Moreover, for convenience and also considering the requirement of the data acquisition and processing, all the earth pressure gauges TY1 TY20 in the roadbed were grouped according to the four depths and were numbered as 1 6, 7 11, 12 16, and 17 20, respectively, for the four depths as shown in Figure 4.

2.3.2. Experimental Procedure. Before beginning the test, strain sensors were connected with a dynamic data acquisition device, which was then connected to a computer through 
TABLE 1: Typical cement pavement structures.

\begin{tabular}{lcccc}
\hline Structural layers & Pavement structure A1 & Pavement structure A2 & Pavement structure A3 & Pavement structure A4 \\
\hline Surface layer & $30 \mathrm{~cm}$ PCC & $26 \mathrm{~cm} \mathrm{PCC}$ & $22 \mathrm{~cm}$ PCC & $18 \mathrm{~cm}$ PCC \\
Base layer & $20 \mathrm{~cm}$ water-stable gravel & $20 \mathrm{~cm}$ water-stable gravel & $20 \mathrm{~cm}$ water-stable gravel & $18 \mathrm{~cm}$ lime soil \\
Subbase layer & $30 \mathrm{~cm}$ lime soil & $20 \mathrm{~cm}$ lime soil & - & - \\
Roadbed & $330 \mathrm{~cm}$ compacted soil & $330 \mathrm{~cm}$ compacted soil & $330 \mathrm{~cm}$ compacted soil & $330 \mathrm{~cm}$ compacted soil \\
\hline
\end{tabular}

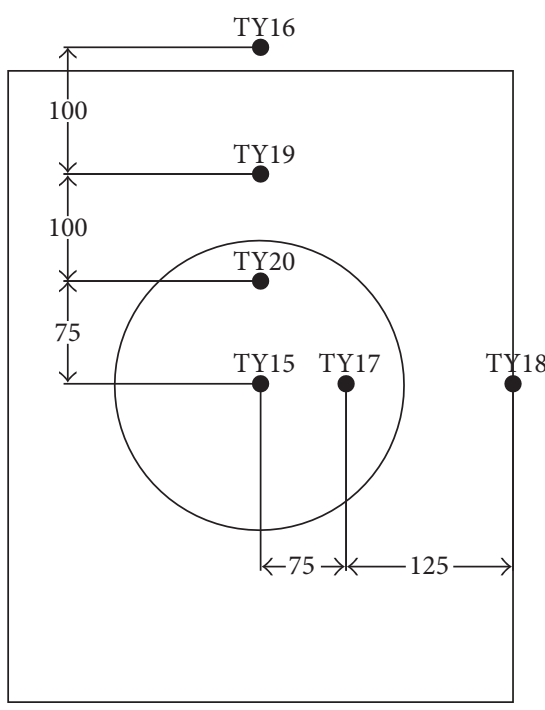

(a) Layout of sensors at depth $Z=0$

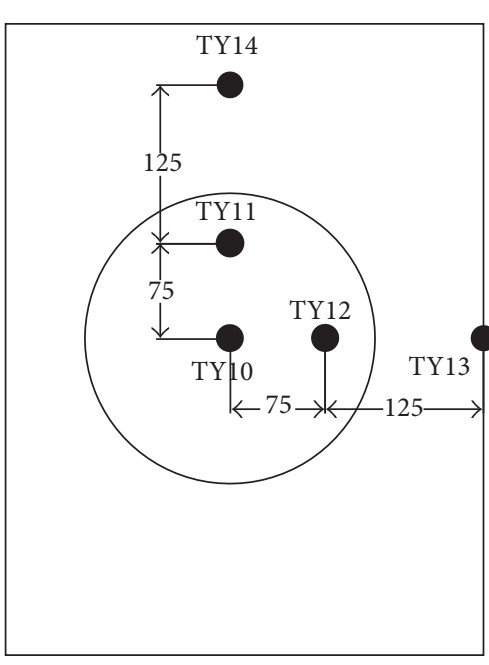

(b) Layout of sensors at the position $Z=100$

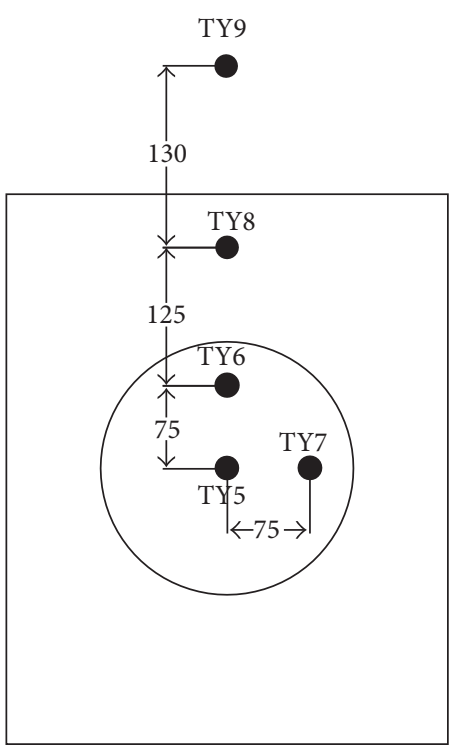

(c) Layout of sensors at the position $Z=$ 200

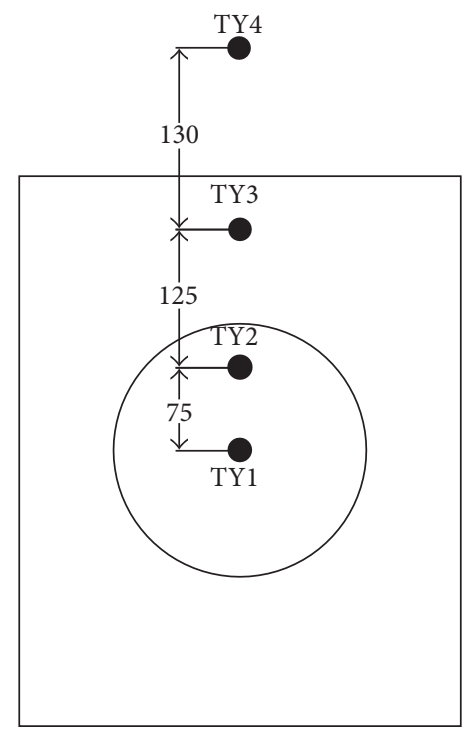

(d) Layout of sensors at the position $Z=$ 300

FIGURE 4: Layout of strain sensors in concrete base layer along its depth.

an USB interface. The data measurement and acquisition system was debugged until it worked normally.

According to the loading point scheme mentioned above, the position of the loading point was determined by using a steel ruler and other measurement tools. The loading devices were fixed on the II-shape tie-beam as shown in Figure 2 for applying the load in accordance with the established loading scheme as shown in Figure 1.

The loading system and the data measurement and acquisition system were tested by imposing a small load 


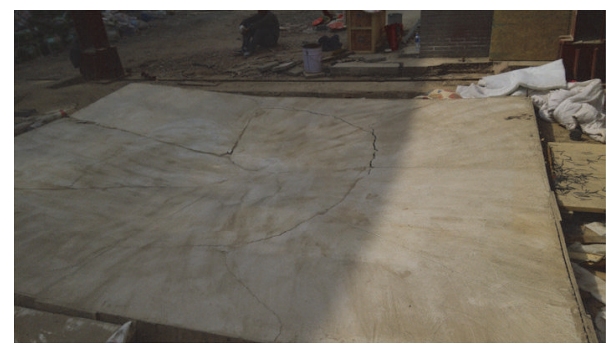

FIGURE 5: Cracking and warping of the edges of a cement concrete slab.

for prepressing the slab to verify whether the whole test system was in the normal working condition. The following procedures were continued only after this verification.

According to the loading scheme considered, a control system was used for the loading device to conduct the impact loading test based on the established load spectrum as shown in Figure 1 and then to conduct the loading test for a static heavy load.

During the loading process, data sampling was closely watched to confirm that everything behaved normally. After the loading was over, all the experimental data were saved to the connected computer.

2.3.3. Experimental Analysis. In the four full-scale threedimensional test slot loading tests, observations were made for cracks, vertical displacement, and warping of the edges of the cement concrete slab as shown in Figure 5. The observed damage progression is analyzed in detail as follows.

(1) Annular Shear Cracks. As the first visible damage features, semicircular penetrating shear cracks appeared along the longitudinal direction of the cement concrete slabs and they spread towards the slab edges from the periphery of the circular loading ring. Such cracking is attributed to the following three aspects. (i) Since the size of the concrete slabs was relatively smaller than that of the base, the size effect caused the annular shear cracks under the impact load which failed to be distributed on the whole concrete slab. Meanwhile, the annular shear cracks and the radial cracks in the transverse direction of concrete slab overlapped, causing the annular shear cracks to directly change their direction to spread towards the slab edges. (ii) The airbag pressure load under the rubber base was nonuniform and the pavement structural materials were also nonuniform, which caused the fact that the semicircular ring of pavement annular shear cracks did not appear. (iii) As mentioned above, compared with that of actual load, the impact effect of the test load was relatively weaker, which is also an important reason why the annular shear cracks failed to spread on the whole concrete slab. Measurement of the annular shear cracks revealed that the crack width reached up to $1 \mathrm{~cm}$ and was wider compared to the radial crack.

In combination with the failure modes of pavement structures observed in the experiment, the annular shear crack on the concrete slab was formed in the periphery area that is $15 \sim 35 \mathrm{~cm}$ away from the round base due to the strong impact effect of the rubber base. Therefore, the concrete slab in the pavement structure was subjected to shear action under the strong impact load. Such a shear cracking of the pavement structure is quite different from the cracking under traffic loads in which fatigue effects due to traffic load and thermal cracks should be considered. Moreover, this observation indicates that the impact and the shear action of the impact load on the pavement structure can directly destroy a typical pavement structure by causing vertical direct shear cracks.

(2) Radial Cracks. Under the impact load, a large number of radial penetrating cracks were formed along the radial direction of the concrete slab. In the test site, slight cracks were also observed on the destructed pavement. Through an analysis, it was known that the radial penetrating cracks on the concrete slab were caused by the fact that after the strong impact load was imposed on the pavement, the pavement structure was compressed, causing tensile failure and cracks at the bottom of the cement concrete slab and then causing radial penetrating cracks to appear on the surface of the concrete pavement. According to the analysis, the mechanism of formation of this kind of pavement failure mode was in agreement with the failure mechanism under loads specified in design specifications of cement concrete road pavement. They are both caused by the tensile cracks at the bottom of the cement concrete slabs subjected to compression on the pavement surface. This indicates that the radial cracks are formed from bottom to top. Therefore, the width of radial cracks as appeared on the pavement surface was smaller than that of radial shear cracks.

(3) Vertical Settlement of the Pavement Structures. The vertical settlement of the whole pavement structure was measured by comparing the vertical spacing between the pavement and rubber base before and after the experiment. Since its value was relatively large in the range of few $\mathrm{cm}$, it was measured by using a steel ruler. The vertical settlement of the base center was calculated by measuring its vertical spacing with respect to the edges of the rubber base. Before the experiment, the initial vertical spacing at the edges of rubber base was about $5 \mathrm{~m}$ when the loading devices were installed. Therefore, the vertical settlement of the rubber base edges was obtained by subtracting the initial spacing from the spacing after the experiment.

(4) Warping of the Edges of the Cement Concrete Slabs. Under an impact load, cement concrete slab edges can warp, which is different from the fatigue failure in highway pavements under coupling effects of load, temperature, water, and other factors. That is because the destruction of pavement structures under an impact load belongs to strength failure unlike fatigue failure.

In summary, under the impact load in an actual experiment, the failure modes of typical pavement structures mainly included annular shear cracks, radial cracks, vertical settlement of the pavement, and warping of the edges of the cement concrete slabs. The impact load caused obvious effects of impact on the pavement structures and the failure modes differed from the fatigue failure under regular traffic loads. 
TABLE 2: CDP basic parameters.

\begin{tabular}{lcccc}
\hline $\begin{array}{l}\text { Parameter } \\
\text { name }\end{array}$ & $\begin{array}{c}\text { Dilatancy } \\
\text { angle }\end{array}$ & $\begin{array}{c}\text { Flow } \\
\text { potential } \\
\text { offset }\end{array}$ & $\begin{array}{c}\text { Ultimate } \\
\text { strength ratio } \\
\text { of biaxial and } \\
\text { uniaxial } \\
\text { compression }\end{array}$ & $\begin{array}{c}\text { Invariant } \\
\text { stress ratio }\end{array}$ \\
\hline Value & $30^{\circ}$ & 0.1 & 1.16 & 0.6667 \\
\hline
\end{tabular}

The damage under impact load belonged to strength failure in which the stresses surpassed the ultimate strengths of the pavement materials. The annular shear cracks were formed from top to bottom with relatively larger widths, while radial cracks were formed from bottom to top with relatively smaller widths. Moreover, the formation mechanisms of the two kinds of cracks were markedly different.

\section{Mechanical Pavement Model}

In the finite element calculation, the surface layer was analyzed using the cement concrete damaged plasticity model (CDP model). Dynamic modulus was adopted for the lime soil in the base layer and the extended Drucker-Prager (D-P) model was adopted for the roadbed.

3.1. Damaged Plasticity Model. Concrete damaged plasticity model (CDP model $[10,16,17])$ was developed based on the models by Lubliner [11] and Lee and Fenves [12]. This model is based on the basic assumption that the isotropic damage inside the materials is the same. It adopts the isotropic elastic damage model and combines it with plastic deformation to simulate the inelastic behavior of concrete. Its advantage is that it is applicable for all forms of load. After concrete material is subjected to external loads and the material deformation exceeds the elastic stage, CDP model will bring in a damage factor to describe the material's deformation in the inelastic stage. At this time, the expression for elastic modulus $E$ is shown as follows:

$$
E=(1-q) E_{0},
$$

where $E_{0}$ represents the initial elastic modulus and $q$ represents the damage factor in tension or compression. The range for damage factor $q$ is $(0,1)$; when $q=0$, the material is not damaged; and when $q=1$, the material is completely damaged and does not have any load carrying capacity.

The primary data to input the CDP model in the finite element software ABAQUS are listed in Table 2.

\subsection{Drucker-Prager (D-P) Model for the Roadbed. Finite} element software ABAQUS has extended the Drucker-Prager (D-P) model and has classified the extended model into three variations, they are exponential function model, linear function model, and hyperbolic function model, according to the different shapes of the yield surface on the meridian plane. Because the hyperbolic function model and the exponential function model are only applicable for the standard model and the explicit model as adopted in this paper to simulate the dynamic instantaneous load, linear Drucker-Prager model $[11-13,18]$ was used for the roadbed.
3.2.1. Yield Surface. The function for the yield surface in the linear D-P model is shown as follows:

$$
F=t-p \tan \beta-d
$$

where $t=(q / 2)\left[1+1 / k-(1-1 / k)(r / q)^{3}\right] ; \beta$ represents the dip angle of the yield surface in the $p \sim t$ stress space, and it is related to friction coefficient $\varphi ; k$ is the ratio of tensile strength and compressive strength under the condition of triaxial stress, with its value stipulated as $0.778 \leq k \leq 1$; and $d$ represents the intercept of yield surface in the $p \sim t$ stress space and it can be determined through the following 3 formulas:

Based on the uniaxial compressive strength $\sigma_{c}$, it can be defined as $d=(1-1 / 3 \tan \beta) \sigma_{c}$.

Based on the uniaxial tensile strength $\sigma_{t}$, it can be defined as $d=(1 / k+1 / 3 \tan \beta) \sigma_{t}$.

Based on the shear strength $\tau$, it can be defined as $d=$ $(\sqrt{3} / 2) \tau(1+1 / k)$.

3.2.2. Plastic Potential Surface. The function of plastic potential surface of the linear Drucker-Prager model is expressed as

$$
G=t-p \tan \Psi
$$

where $t$ stands for the measurement parameter of deviatoric stress; $p$ is the equivalent compressive stress; and $\Psi$ is the expansion angle.

A hardening law was defined to control the size of the yield surface. The yield surface size of the D-P model in ABAQUS was controlled by an equivalent effective stress $\bar{\sigma}$ and was controlled by inputting the relationships of $\bar{\sigma}$ with an equivalent plastic strain $\overline{\mathcal{\varepsilon}}^{\mathrm{pl}}$ in ABAQUS. The equivalent effective stress $\bar{\sigma}$ can be determined by three methods, namely, uniaxial compressive strength, tensile strength, and cohesive strength.

3.2.3. Calculation Parameters. The D-P model included five parameters: cohesive strength $c$, internal friction angle $\varphi$, elastic modulus $E, K$, and $\beta$. The calculating methods for $K$ and $\beta$ are given as

$$
\begin{aligned}
K & =\frac{3-\sin \varphi}{3+\sin \varphi}, \\
\tan \beta & =\frac{6 \sin \varphi}{3-\sin \varphi} .
\end{aligned}
$$


TABLE 3: Basic parameters in the D-P model of the Shaanxi loess.

\begin{tabular}{lcccccc}
\hline Name & Cohesive strength $c$ & Internal friction angle $\varphi$ & Elastic modulus $E$ & $K$ & $\beta$ & $\Psi$ \\
\hline Value & $47.57 \mathrm{kPa}$ & $25.61^{\circ}$ & $100 \mathrm{MPa}$ & 0.778 & $45.28^{\circ}$ & $20^{\circ}$ \\
\hline
\end{tabular}

TABLE 4: The natural frequencies for five modes in the pavement model.

\begin{tabular}{|c|c|c|c|c|c|}
\hline Order $n$ & 1 & 2 & 3 & 4 & 5 \\
\hline Circular frequency $\omega_{i} /\left(\mathrm{rad} \cdot \mathrm{s}^{-1}\right)$ & 116.16 & 173.51 & 228.31 & 235.68 & 258.96 \\
\hline Frequency $f_{i} / \mathrm{Hz}$ & 18.488 & 27.614 & 36.337 & 37.509 & 41.214 \\
\hline
\end{tabular}

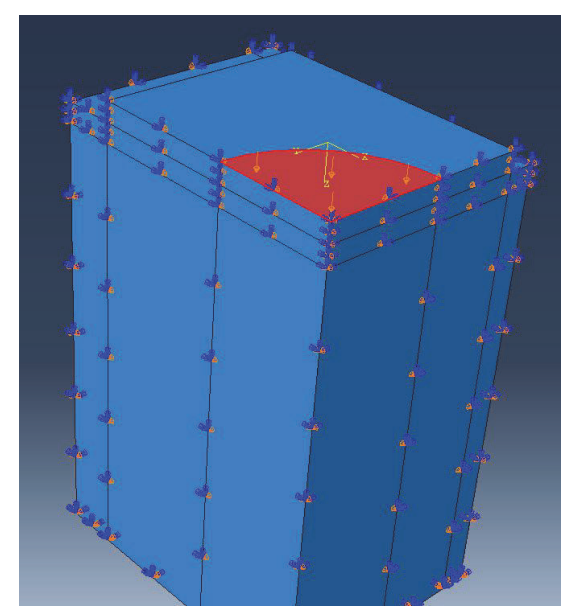

FIGURE 6: Sketch of the load position in three-dimensional test slot experiment.

Based on the review of literature about loess in Shaanxi, basic mechanical parameters of old loess (silty clay) based on Zhang were used. Cohesive strength value was taken as $47.57 \mathrm{kPa}$, and internal friction angle value was taken as $25.61^{\circ}$. The D-P model built for the Shaanxi loess is shown in Table 3.

3.3. Finite Element Model. This study mainly considered the deflection of every structural layer of concrete pavement, the variations in stress and strain, and the thermal stress. With reference to the modeling scheme in the existing literature, three-dimensional hexahedron elements were used in the calculation. "C3D8R" hexahedron elements in ABAQUS [1921] were adopted. The finite element model is shown in Figure 6. Due to the temperature variation, the structure or the element will produce stretch or shrink, which will lead to stress inside the structure or element when the stretch or shrink is limited. The stress produced during this progress is called thermal stress. During the adiabatic analysis, mechanical deformations will produce heat, and the whole process is extremely short, with no diffusion occurring. ABAQUS/Standard or ABAQUS/Explicit could be used to solve this problem.

Considering that the pavement structures and loads were all symmetrical in the experiment, only one-fourth of the pavement structures were modeled. In order to study the dynamic response characteristics of concrete pavement structures under an impact load, the contact surface of the loading device and the surface of the pavement structures were modeled as circles with a diameter of $2 \mathrm{~m}$. The load magnitude was entered as the actual measured value from the three-dimensional test slot experiment.

Under a dynamic load, the dynamic response of pavement structures is largely dependent on their natural frequencies. Therefore, before the simulation, natural frequencies and vibration modes were obtained through a modal analysis. The modal analysis provided vibration parameters for the dynamic analysis of pavement structures and the damping factors of the models. Considering that the load was a vertical impact load, the vertical direction of the pavement was set as the main vibration direction. The calculation results are shown in Table 4.

\section{Numerical Response Analysis}

\subsection{Road Surface Deflection}

4.1.1. Time History Analysis of the Road Surface Deflection. The change in road surface deflection with the duration of load acting at the model's origin point $\mathrm{O}$ is shown in Figure 7. The figure shows that the deflection response is basically consistent with the load curve as shown in Figure 1. The maximum deflection was observed corresponding to the time of $660 \mathrm{~ms}$, when the load began to decline. At $800 \mathrm{~ms}$ when loading was over, pavement structures did not completely recover to the original state and deflection did not recover to zero. It shows that irreversible plastic deformation characteristically occurs in the pavement structures. The majority of the plastic deformation is attributed to the roadbed deformation.

4.1.2. Spatial Distribution Characteristics of Road Surface Deflection. At the time of $660 \mathrm{~ms}$ under the action of the impact load, the cement concrete slab surface in the model exhibited the maximum deflection. The three-dimensional spatial distribution of the maximum road surface deflection for the four concrete pavement structures A1-A4 corresponding to $660 \mathrm{~ms}$ is shown in Figure 8. From the figure, the following laws can be observed.

(1) Under a circular uniform load, the distributions of road surface deflection among four different pavement structures were consistent and they all had the peak deflections. The nearer a point was from the center point of the circular load, the larger was the deflection. Because the strength of four kinds of pavement structures A1-A4 
TABLE 5: Comparison of the maximum deflections $(\mathrm{mm})$ for the four pavement surfaces.

\begin{tabular}{lcccc}
\hline Pavement structure & A1 & A2 & A3 & \\
\hline Original point O & 4.487 & 7.907 & 9.975 & 18.293 \\
Slab corner & -1.444 & -2.881 & -5.637 & -32.051 \\
\hline
\end{tabular}

TABLE 6: Time point of plastic deformation and corresponding load magnitudes.

\begin{tabular}{lcccc}
\hline Pavement structure & A1 & A2 & A3 & \\
\hline Time $(\mathrm{ms})$ & 68 & 60 & 56 & 36 \\
Load $(\mathrm{MPa})$ & 0.344 & 0.291 & 0.270 & 0.142 \\
\hline
\end{tabular}

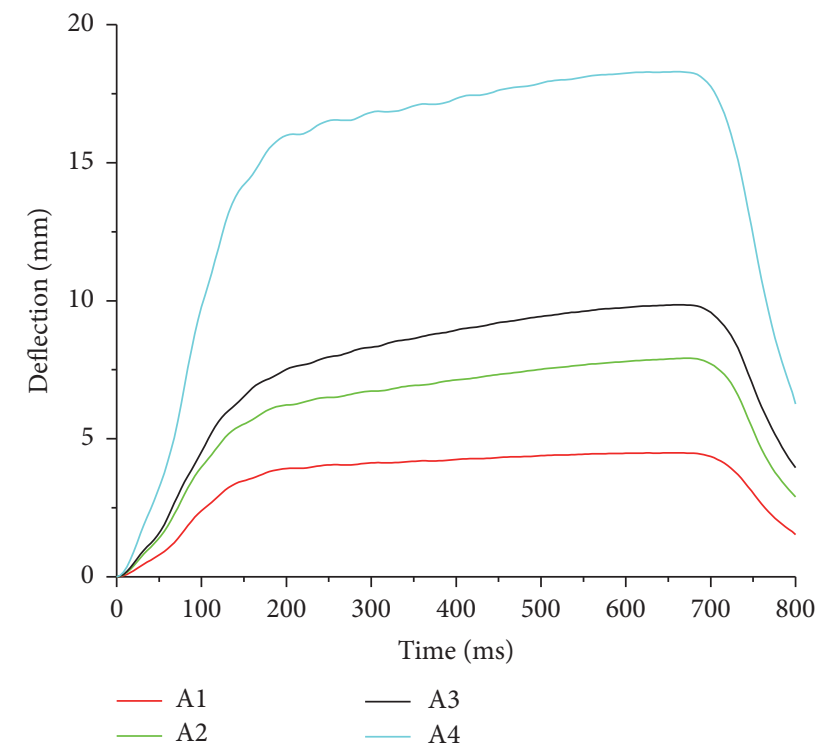

FIGURE 7: Time history curves of deflection from the finite element analysis under the impact load.

decreased in sequence, their integral rigidity also decreased in sequence. Therefore, the change in reflected deflection response increased in sequence.

(2) The bearing capacity of the pavement structure A4 was far from sufficient, so the deflection in the center of pavement slab reaches $18.293 \mathrm{~mm}$. Due to the large deformation, significantly larger warping occurred on the slab edges and the maximum warping reached $27.206 \mathrm{~mm}$. It should be noted that, in the three-dimensional test slot experiment, there were no constraints around the edges of the cement concrete slabs, which is greatly different from the case of highway pavement structures, where dowel bars restrain the edges from wrapping. Because of this difference, slab edge warping was observed in both the field experimental results and the calculation results. Meanwhile, it also shows that the base layer of this kind of pavement structures does not have strong structural integrity.

(3) Peak values of the road surface deflection in the two kinds of pavement structures A2 and A3 were $7.907 \mathrm{~mm}$ and $9.975 \mathrm{~mm}$, respectively. It should be noted that, for A2, $20 \mathrm{~cm}$ lime soil subbase layer was adopted, while for A3 no subbase layer was used as shown in Table 1 . Their deflection does not differ greatly, which shows that even though lime soil subbase layer acts as the functional layer in the pavement structures, it plays a small role in the load bearing process.

For the distribution of three-dimensional space deflection as shown in Figure 8, the largest deflection appeared at the load center, namely, the center of pavement structures. Because pavement structures and load distribution were symmetric, the transverse and longitudinal distributions of road surface deflection had the same shapes, namely, a "U-shape" distribution. Their maximum values were at the load center for both directions. With an increase in the distance from the original position, the deflection decreased significantly. The maximum deflections in the four kinds of pavement structures are shown in Table 5.

4.2. Strain at the Bottom of the Cement Concrete Surface Layer. The deformation process of concrete material under an external force can be divided into elastic stage and plastic stage. In this paper, the load imposed on pavement structures had the features of an impact load. Under this load, most areas of the concrete surface layer reached the plastic stage in the load bearing process.

4.2.1. Analysis of the Strain at the End of the Concrete Surface Layer. By investigating the plastic strain of all areas in four kinds of surface layers, the time point when the plastic deformation began to occur and the corresponding load magnitudes were obtained as shown in Table 6 .

The comparison between the true strain and the plastic strain at the bottom center point of the concrete slab pavement structure $\mathrm{Al}$ is shown in Figure 9. The figure shows that no plastic strain occurred during $0 \sim 68 \mathrm{~ms}$, and the plastic deformation began to occur after $64 \mathrm{~ms}$ (when the impact load reached 0.344 MPa).

4.2.2. Analysis of the Spatial Distribution of the Tensile Strain at the Bottom of the Concrete Surface Layer. For the four kinds of concrete pavement structures A1 A4 having different strengths, the spatial distribution of the tensile strain at the bottom of the surface layer at the time point of $200 \mathrm{~ms}$ is shown in Figure 10. The figure shows that the distributions of the tensile strain at the bottom of the surface layer are generally similar for the four pavement structures. Due to a large integral rigidity of the concrete surface layer, after the load was imposed on the concrete surface layer, tensile stress was mainly produced in the transverse and longitudinal 


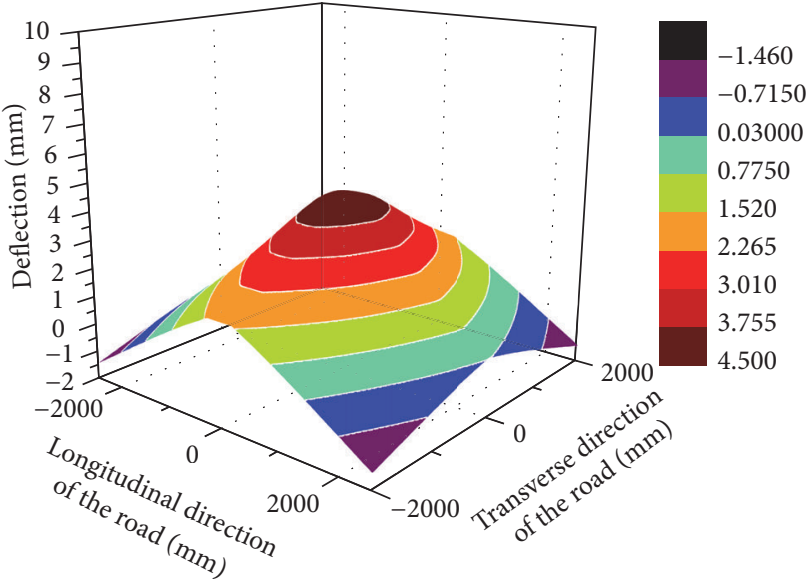

(a) Pavement structure A1

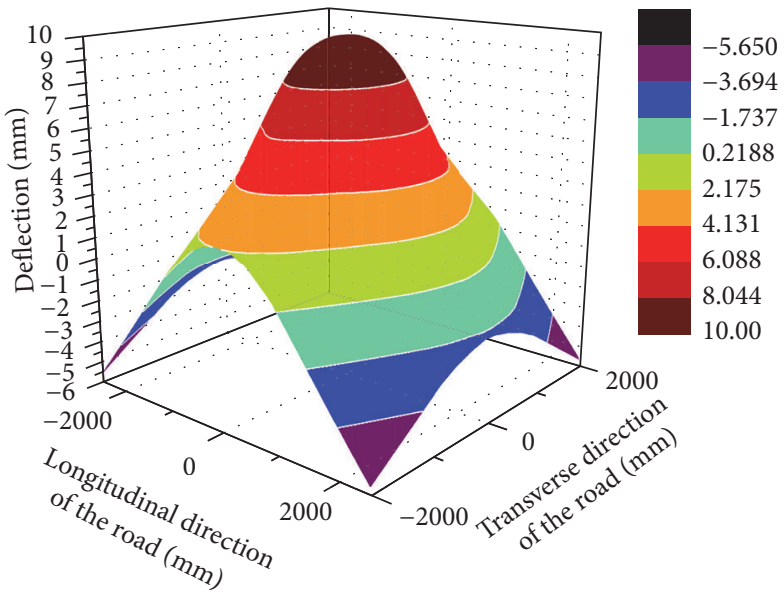

(c) Pavement structure A3

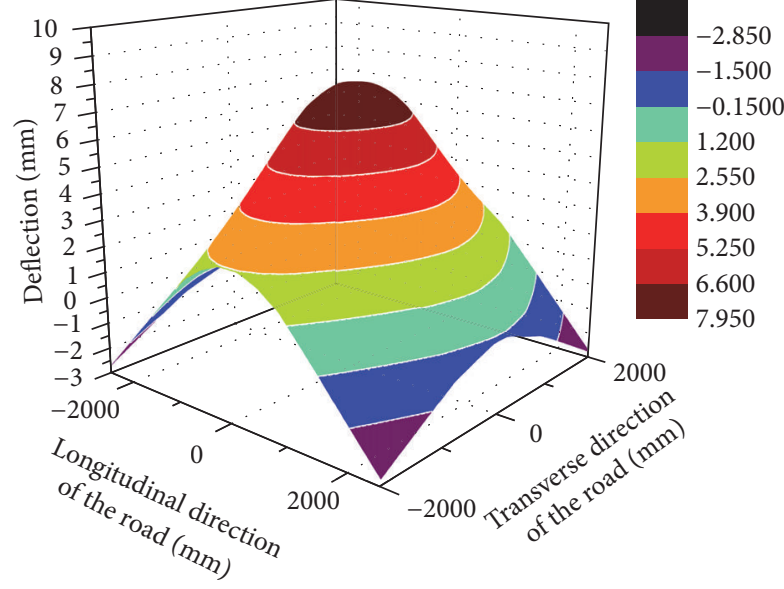

(b) Pavement structure A2

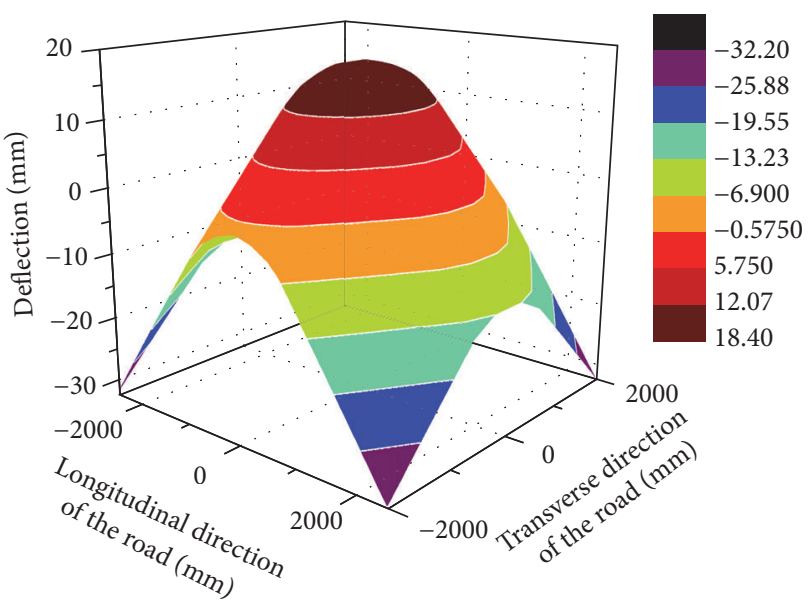

(d) Pavement structure A4

FIGURE 8: Spatial distribution of deflection of the four kinds of pavement structures as obtained from the numerical analysis.

directions. Abrupt change occurred in the tensile strain near the central symmetry axis of the concrete surface layer. Moreover, the closer the distance from origin $\mathrm{O}$ was, the more obvious was the abrupt change. With a decrease in the pavement strength, abrupt change in the tensile strain appeared at increasing locations. These locations indeed represented the positions where cracks occurred.

The distribution of tensile strain at the bottom of the surface layer along the transverse and longitudinal directions of the road (from origin $\mathrm{O}$ ) is shown in Figure 11. Along the transverse direction of road, the maximum tensile strain of the structure A4 occurred at a point $645 \mathrm{~mm}$ from the origin, that of the structure $\mathrm{A} 3$ occurred at a point $322 \mathrm{~mm}$ from the origin, that of A2 occurred at a point $665 \mathrm{~mm}$ from original point $\mathrm{O}$, and that of $\mathrm{Al}$ occurred at a point $87 \mathrm{~mm}$ from original point $\mathrm{O}$. The order of magnitude of the maximum tensile strain was consistent with the order of strength of the pavement structures.

4.3. Plastic Damage Cracking. In this paper, calculation parameters of concrete materials adopted the CDP damaged plasticity model. It not only defined values of concrete plastic strain under different stress conditions but also utilized the definition of damage factor to predict the time and position of cracking in concrete slab. Figure 12 shows the damage distribution at the bottom of the surface layer in the four concrete pavement structures. The definition of concrete damage only shows the cracking degrees under different degrees of plastic strain, and the load bearing capacity of the slabs would not change with that. Therefore, the CDP model cannot predict the change in stress conditions after concrete surface was cracked partially.

By observing the surface layer damage under the same load, it was found that the load bearing capacity of structure $\mathrm{A} 1$ was the largest, that of A4 was the lowest, and those of A2 and $\mathrm{A} 3$ were intermediate and similar to each other. Concrete damage was located mainly within the loading areas and near the transverse central line and the longitudinal center line of the concrete slab. The cracking mechanism was basically in accordance with the mechanism of crack development as observed in the three-dimensional test slot experiment. 


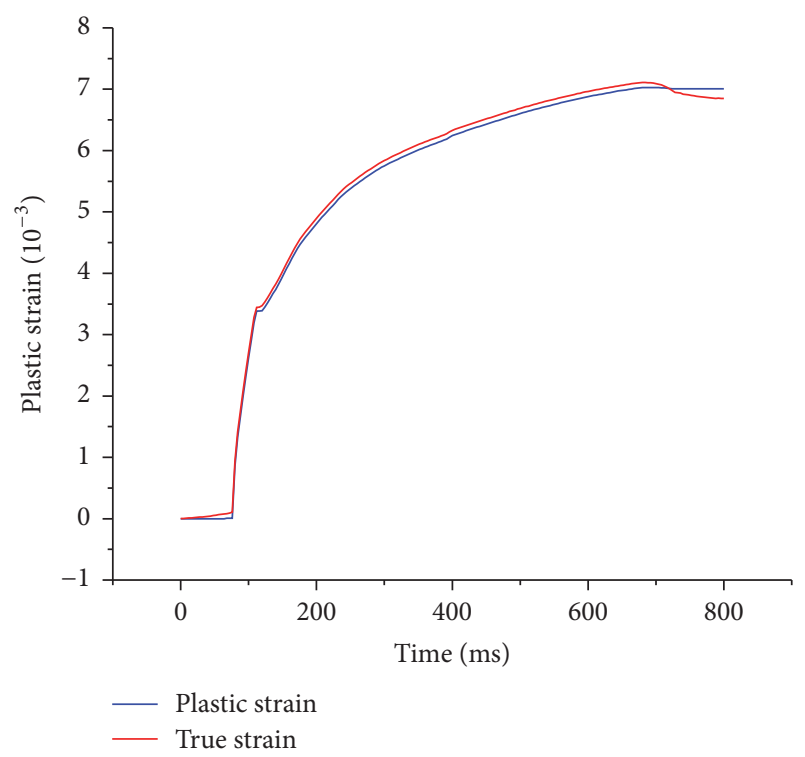

FIGURE 9: Comparison of the true strain and the plastic strain in A1.

TABLE 7: Comparison of the numerical and experimental values of strains $\left(10^{-6}\right)$ in the surface layer under $0.1 \mathrm{MPa}$.

\begin{tabular}{lccc}
\hline Sensor position & Calculated value & Measured value & Error \\
\hline M1 & 67.669 & 64.062 & $5.63 \%$ \\
M2 & 49.124 & 44.809 & $9.63 \%$ \\
M3 & 52.440 & 47.668 & $10.01 \%$ \\
M4 & 58.272 & 53.515 & $8.89 \%$ \\
M5 & 16.452 & 14.305 & $15.01 \%$ \\
M6 & 32.429 & 28.307 & $14.56 \%$ \\
M7 & -7.387 & 0.000 & - \\
M8 & -2.746 & 0.000 & - \\
\hline
\end{tabular}

The plastic damage at the bottom of the slab in the pavement structure A4 during $0-800 \mathrm{~ms}$ is shown in Figure 13. Before $28 \mathrm{~ms}$, that is, before the load of $0.104 \mathrm{MPa}$, concrete surface layer was in the elastic stage and no damage occurred. Between $28 \mathrm{~ms}$ and $67 \mathrm{~ms}$, load increased from $0.104 \mathrm{MPa}$ to $0.343 \mathrm{MPa}$, and radial damage zones occurred on the concrete surface layer. At $150 \mathrm{~ms}$, a relatively large number of annular damage zones occurred at the bottom of concrete slab, and the concrete slab was basically damaged. With the continuous action of load, the damage at the bottom of the surface layer gradually spread to the top of surface layer. The damage condition is shown in Figure 13(d).

\section{Analysis of Key Mechanical Indices}

In order to verify the consistency between the numerical analysis results and the experimental results, the measured and calculated values of strains were compared at corresponding positions of every sensor in the surface layer and roadbeds of concrete pavement structures. Corresponding percentage errors were computed. Because damage occurred only after plastic deformation occurred in concrete surface layer under a relatively heavy load, no peak strain was
TABLE 8: Comparison of calculated values and measured values $(\mathrm{MPa})$ of vertical stress in the roadbed under $0.74 \mathrm{MPa}$.

\begin{tabular}{lccc}
\hline Sensor's position & Calculated value & Measured value & Error \\
\hline TY1 & -0.055 & -0.050 & $9.32 \%$ \\
TY2 & -0.051 & -0.046 & $11.27 \%$ \\
TY3 & -0.035 & -0.030 & $14.78 \%$ \\
TY4 & -0.026 & -0.022 & $14.38 \%$ \\
TY5 & -0.089 & -0.081 & $9.38 \%$ \\
TY6 & -0.078 & -0.070 & $10.23 \%$ \\
TY7 & -0.079 & -0.070 & $11.06 \%$ \\
TY8 & -0.033 & -0.028 & $13.01 \%$ \\
TY9 & -0.013 & -0.011 & $14.69 \%$ \\
TY10 & -0.178 & -0.164 & $7.65 \%$ \\
TY11 & -0.132 & -0.119 & $9.63 \%$ \\
TY12 & -0.132 & -0.119 & $10.08 \%$ \\
TY13 & -0.035 & -0.030 & $12.35 \%$ \\
TY14 & -0.020 & -0.018 & $13.69 \%$ \\
TY15 & -0.229 & -0.216 & $5.42 \%$ \\
TY16 & 0.002 & 0 & - \\
TY17 & -0.209 & -0.194 & $6.89 \%$ \\
TY18 & -0.003 & -0.002 & $7.01 \%$ \\
TY19 & -0.007 & -0.006 & $10.16 \%$ \\
TY20 & -0.237 & -0.218 & $8.03 \%$ \\
\hline
\end{tabular}

detected. Therefore, the verification of tensile strain at the bottom of the concrete surface layer utilized the experimental data obtained in the device debugging stage, that is, under a load of $0.1 \mathrm{MPa}$. The comparison results are shown in Table 7. In the complete test (under the load of $0.74 \mathrm{MPa}$ ), the earth pressure had a relatively stable peak value and the comparison results are shown in Table 8.

Because there were many influencing factors in the experiment, and particularly the impact load caused obvious damage to the concrete slabs, sensors failed to detect stable strain value. Therefore, parts of stress-strain positions were positive and strains could not be monitored at the bottom of the surface layer and at the lime soil base under heavy loads. From Figures 10 and 11, it is known that test errors at most of the positions were around $10 \%$ and did not exceed $15 \%$ at most, which meets the engineering requirements for such types of analysis.

As to the displacement of slab corners, the threedimensional test slot experiment revealed that the displacement of slab corner was clearly noticeable due to relatively poor bonding condition between the concrete surface layer and the base layer. The experimentally measured interspace heights between the four slab corners and the base layer are shown in Table 9. By comparing them with the numerical results, the errors were found to lie within $15 \% .15 \%$ is a frequently used range in the engineering application, as well as an experience value in engineering practice, which met the test requirements in this work. In other words, $15 \%$ is adopted according to investigation of the construction site. 


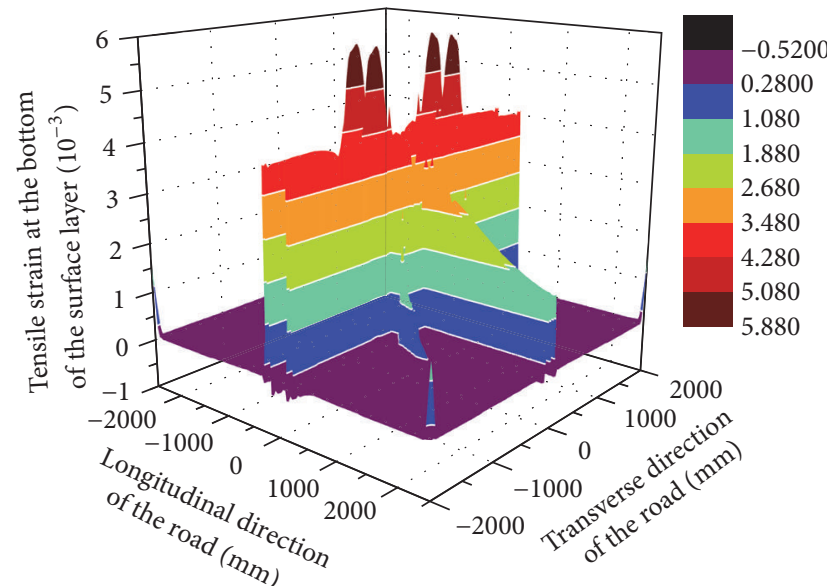

(a) Pavement structure A1

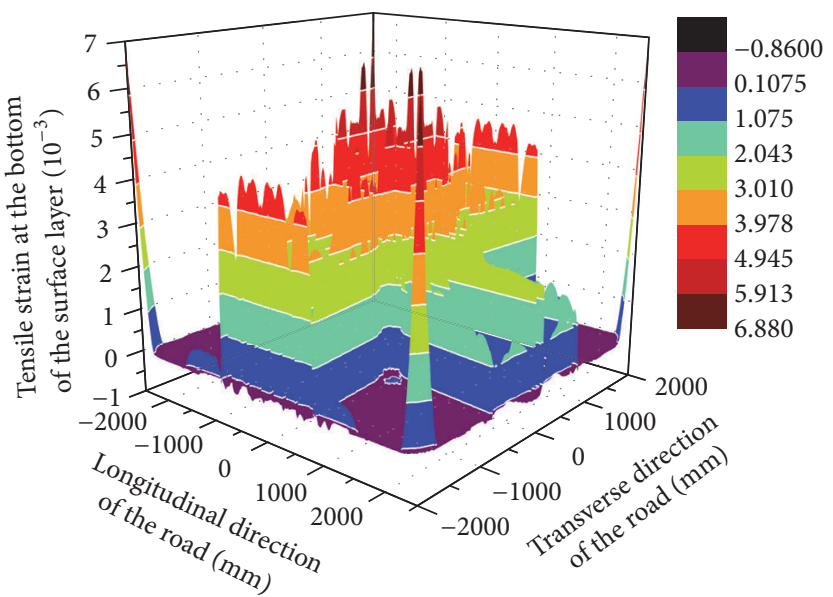

(c) Pavement structure A3

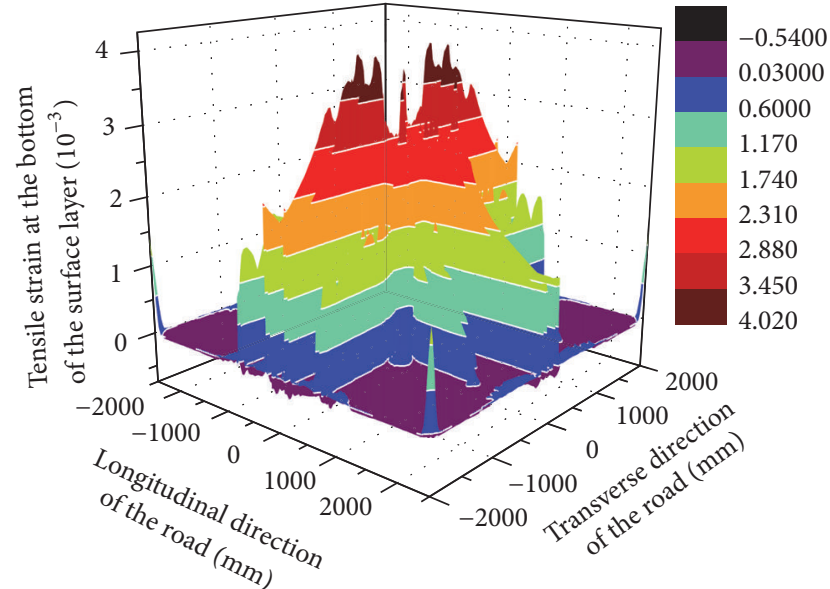

(b) Pavement structure A2

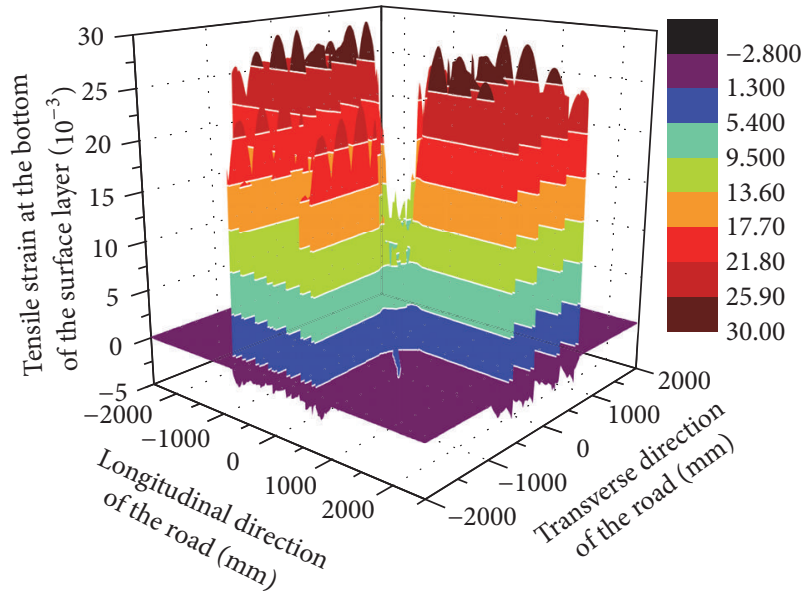

(d) Pavement structure A4

Figure 10: Distribution of stress at the bottom of the surface layer of the four concrete pavements.

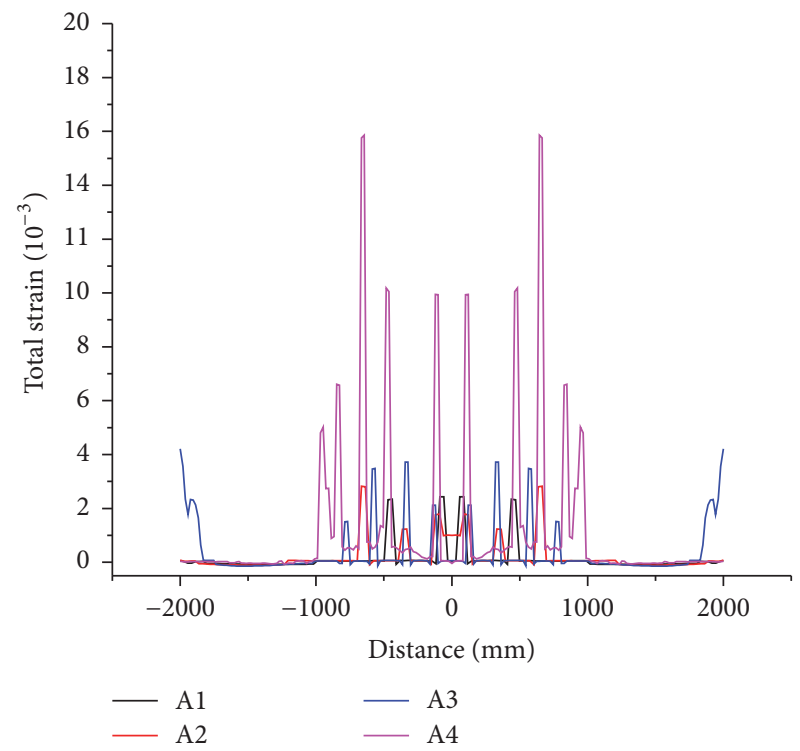

(a) Transverse direction of the road

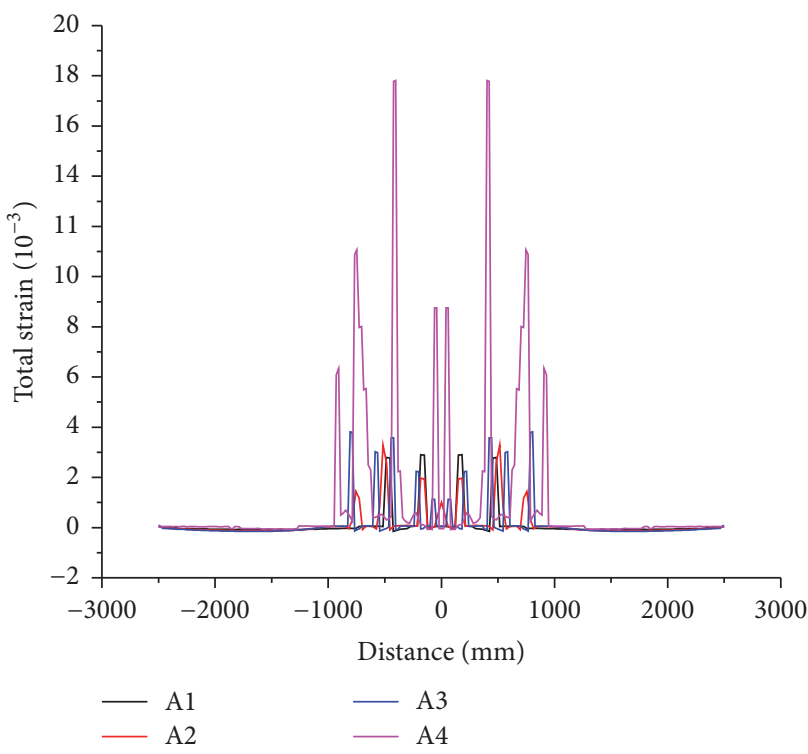

(b) Longitudinal direction of the road

FIGURE 11: Distribution of the tensile strain at the bottom of the surface layer along the transverse and longitudinal directions. 

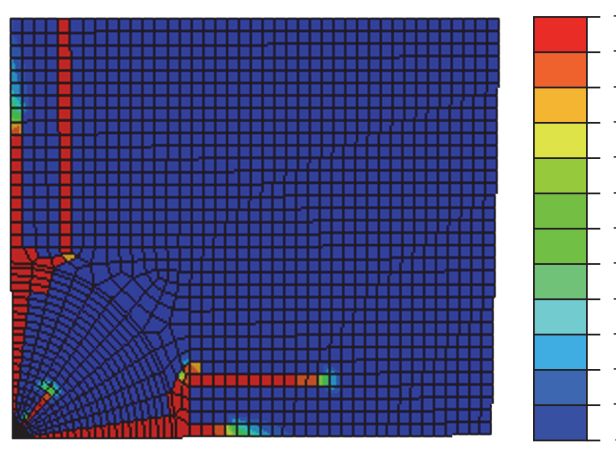

(a) Pavement structure A1
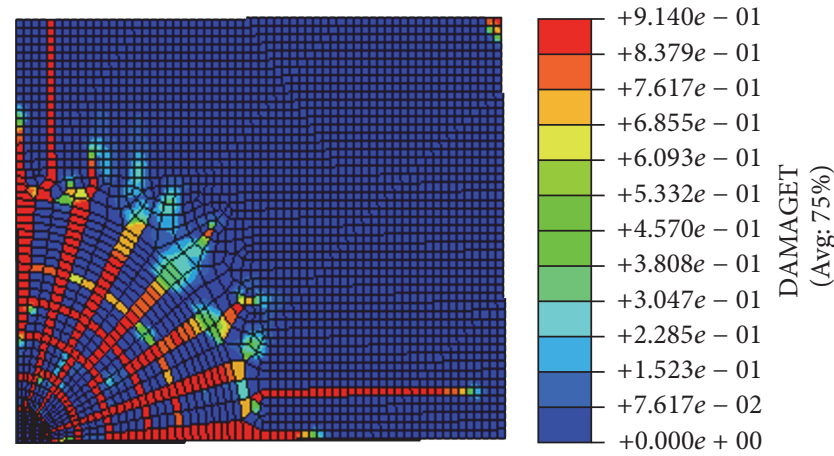

(c) Pavement structure A3
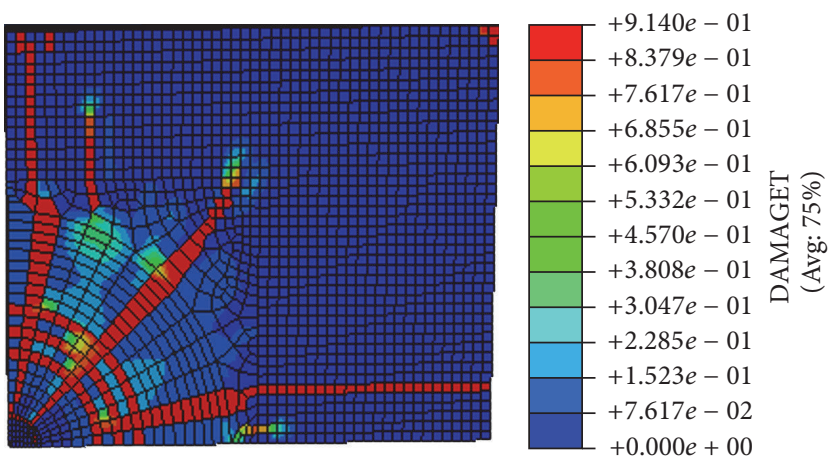

(b) Pavement structure A2
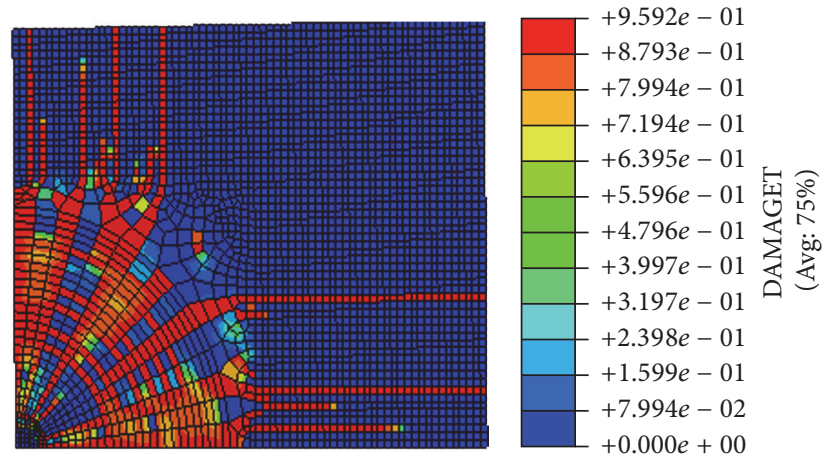

(d) Pavement structure A4

FIGURE 12: Contour of damage distribution at the bottom of the surface layer of the four pavements at $200 \mathrm{~ms}$.
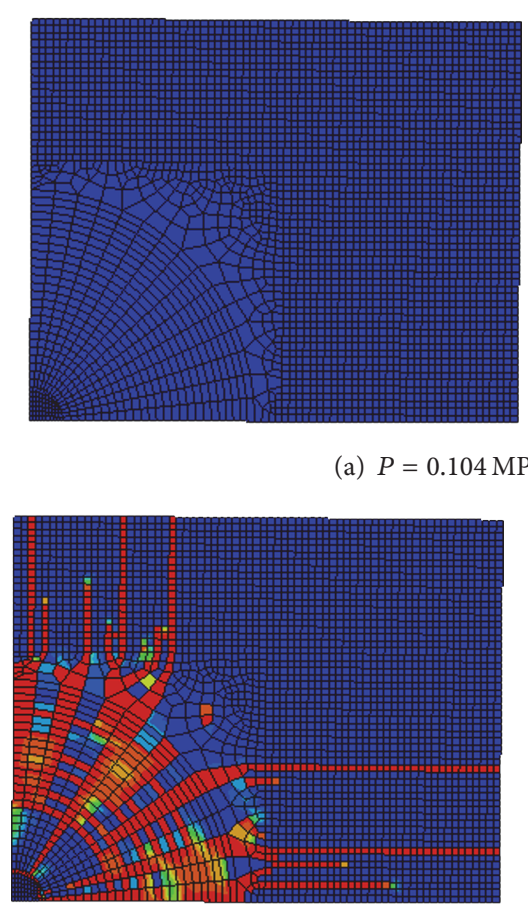

(a) $P=0.104 \mathrm{MPa}$

(c) $P=0.7 \mathrm{MPa}$

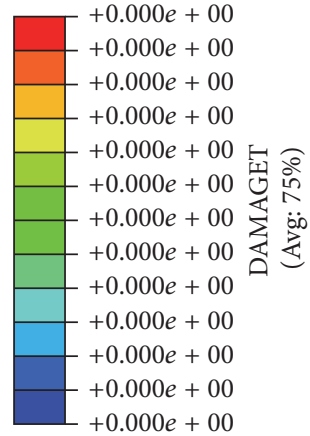

$+0.000 e+00$

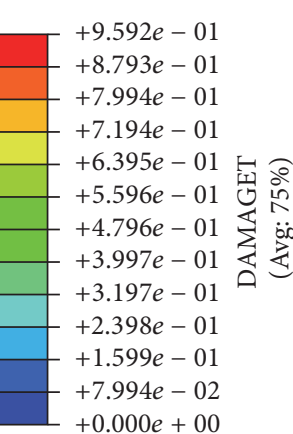

$+0.000 e+00$

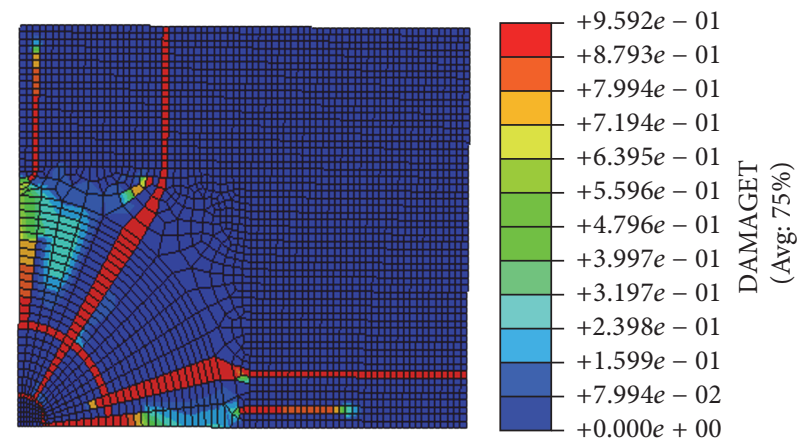

(b) $P=0.343 \mathrm{MPa}$
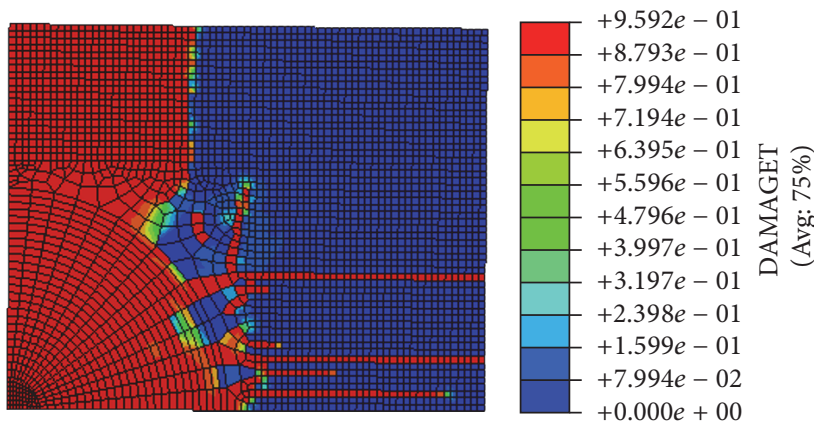

(d) $P=0.74 \mathrm{MPa}$

FIGURE 13: Contour of damage distribution at the bottom of the surface layer in the pavement structure A4 during $0 \sim 800 \mathrm{~ms}$. 
TABLE 9: Interspace height values of concrete slab corners.

\begin{tabular}{lcccc}
\hline Slab corner position & A & B & C & D \\
\hline $\begin{array}{l}\text { Measured value }(\mathrm{mm}) \\
\text { Calculated value }(\mathrm{mm})\end{array}$ & 26 & 27 & 21 & 22 \\
Error & $7.3 \%$ & $10.8 \%$ & 24.092 & \\
\hline
\end{tabular}

\section{Conclusions}

We conclude the following:

(1) By carrying out modeling calculation for four most typical kinds of cement concrete pavement structures in China, this paper studied the mechanical response of cement concrete pavement structures under an impact load. Mechanical characteristics of the slabs were determined which included deflection distribution of the surface layer in the concrete pavements, strain distribution at the bottom of the slabs, and plastic damage and cracking under a dynamic impact load. Under a circular uniform load, the distributions of road surface deflection among four different pavement structures were consistent and they all had the peak deflections. The nearer a point was from the center point of the circular load, the larger was the deflection. Because the strength of four kinds of pavement structures A1-A4 decreased in sequence, their integral rigidity also decreased in sequence. Therefore, the change in reflected deflection response increased in sequence.

(2) By analyzing the results from a three-dimensional test slot experiment and a finite element analysis, the calculation results from the analysis were verified. The finite element model built in this paper could effectively reproduce the response of test pavement structures in an actual loading scenario. The largest deflection appeared at the load center, namely, the center of pavement structures. Because pavement structures and load distribution were symmetric, the transverse and longitudinal distributions of road surface deflection had the same shapes, namely, a "Ushape" distribution. Their maximum values were at the load center for both directions. With an increase in the distance from the original position, the deflection decreased significantly.

(3) The peak values of the stress-strain curves from every sensor were compared and analyzed. The errors of the numerical results were mostly within $10 \%$, indicating that the calculation results were reasonably accurate, showing that the numerical model could reasonably simulate the experimental condition and meet requirements of the experiment.

(4) In this paper, a three-dimensional test slot experiment was performed as an experimental basis. However, the selected pavement structures were all made of cement concrete. In the future, it is recommended to carry out similar experiments on the frequently used asphalt pavement and composite pavement. Further experiments will help to reasonably modify the proposed numerical model and the material parameters based on the newly available experimental data.

\section{Competing Interests}

The authors declare that there are no competing interests regarding the publication of this paper.

\section{Acknowledgments}

Special thanks should go to my friend Dr. Yi Qiao and Dr. Peng Wang who has put considerable time and effort in the proofreading work.

\section{References}

[1] H. Qin and X. Z. Zhao, "Study on the ABAQUS damage parameter in the concrete damage plasticity model," Structural Engineers, vol. 29, no. 6, pp. 27-32, 2013 (Chinese).

[2] M. Cao, "Research on damage plastic calculation method of ABAQUS concrete damaged plasticity model," Communications Standardization, vol. 2, pp. 51-54, 2012 (Chinese).

[3] R. Salsilli, C. Wahr, R. Delgadillo, J. Huerta, and P. Sepúlveda, "Field performance of concrete pavements with short slabs and design procedure calibrated for Chilean conditions," International Journal of Pavement Engineering, vol. 16, no. 4, pp. 363379,2015

[4] M. E. Bari and D. G. Zollinger, "New concepts for the assessment of concrete slab interfacial effects in pavement design and analysis," International Journal of Pavement Engineering, vol. 17, no. 3, pp. 233-244, 2016.

[5] J. M. Vandenbossche, F. Mu, and T. R. Burnham, "Comparison of measured vs. predicted performance of jointed plain concrete pavements using the Mechanistic-Empirical Pavement Design Guideline," International Journal of Pavement Engineering, vol. 12, no. 3, pp. 239-251, 2011.

[6] C. H. Liu, The Research of Structure Analysis of Cement Concrete Pavement under Heavy Load Traffic, Hunan University, Changsha, China, 2000 (Chinese).

[7] Z. Li, Study on Structure Design and Construction of Key Technology of Heavy Traffic Cement Concrete Pavement, Chang'an University, Xi'an, China, 2012 (Chinese).

[8] X.-C. Wang and R.-G. Hou, "Structure design of long-life pavement," Journal of Traffic and Transportation Engineering, vol. 7, no. 6, pp. 46-49, 2007.

[9] C. Xiao, Research on Dynamic Behavior and Structure Optimization for Typical Asphalt Pavement, Southwest Jiaotong University, 2014 (Chinese).

[10] J. Zhang, J. Li, and J. W. Ju, “3D elastoplastic damage model for concrete based on novel decomposition of stress," International Journal of Solids and Structures, vol. 94-95, pp. 125-137, 2016. 
[11] F. Parker Jr., R. W. Barker, C. R. Gunkel et al., "Development of a structural design procedure for rigid airport pavements," Tech. Rep. TRGL-79-4, U.S. Army Engineer Waterways Experiment Station (WES), Vicksburg, Miss, USA, 1979.

[12] T. Bennert and A. Maher, "Field and laboratory evaluation of a reflective crack interlayer in New Jersey," Transportation Research Record, no. 2084, pp. 114-123, 2008.

[13] P. Liu, The Force Impact Analysis of Cement Concrete Pavement on Different Combination States, Changan University, Xian, China, 2013 (Chinese).

[14] Y. Q. Pan and J. Yang, "Research status of full-scale accelerated pavement testing in China and aborad," Journal of China \& Foreign Highway, vol. 25, no. 6, pp. 137-140, 2005.

[15] J. Q. Yang, Strain Transfer Theory and Sensing Property Research of Strain Sensor, Central South University, Changsha, China, 2013 (Chinese).

[16] A. S. Genikomsou and M. A. Polak, "Finite element analysis of punching shear of concrete slabs using damaged plasticity model in ABAQUS," Engineering Structures, vol. 98, pp. 38-48, 2015.

[17] U. Häussler-Combe and E. Panteki, "Modeling of concrete spallation with damaged viscoelasticity and retarded damage," International Journal of Solids and Structures, vol. 90, pp. 153166, 2016.

[18] X. H. Li, Numerical Analysis on Cracking and Seating Existing Cement Concrete Pavement with Impact Compaction, South China University of Technology, 2011 (Chinese).

[19] S. P. Yang, S. H. Li, and Y. J. Lu, "Investigation on dynamical interaction between a heavy vehicle and road pavement," Vehicle System Dynamics, vol. 48, no. 8, pp. 923-944, 2010.

[20] G. Galli, A. Grimaldi, and A. Leonardi, “Three-dimensional modelling of tunnel excavation and lining," Computers and Geotechnics, vol. 31, no. 3, pp. 171-183, 2004.

[21] M. I. Hammons, "Validation of three-dimensional finite element modeling technique for joints in concrete airport pavements," Transportation Research Record, no. 1629, pp. 67-75, 1998. 


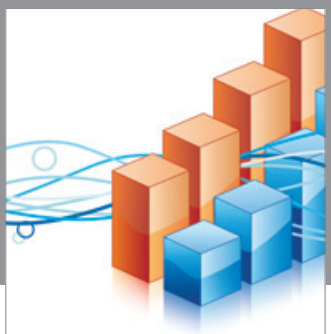

Advances in

Operations Research

vatem alat4

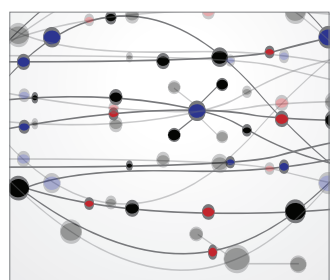

\section{The Scientific} World Journal
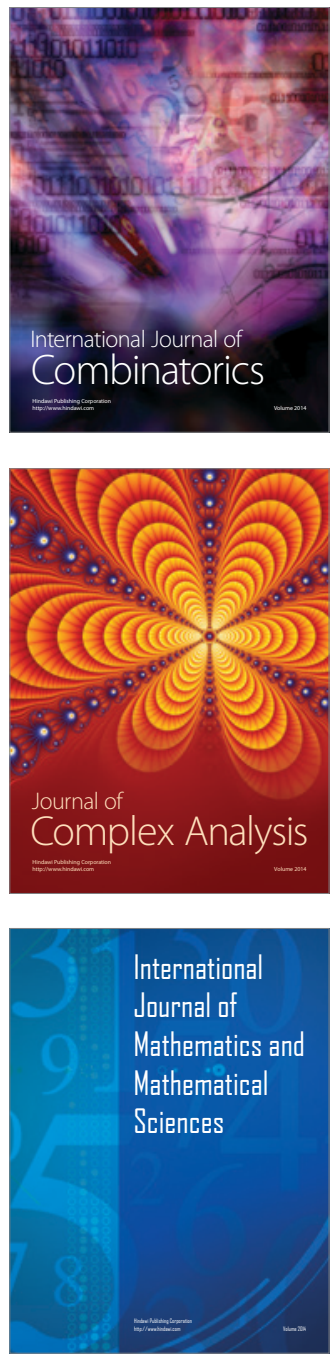
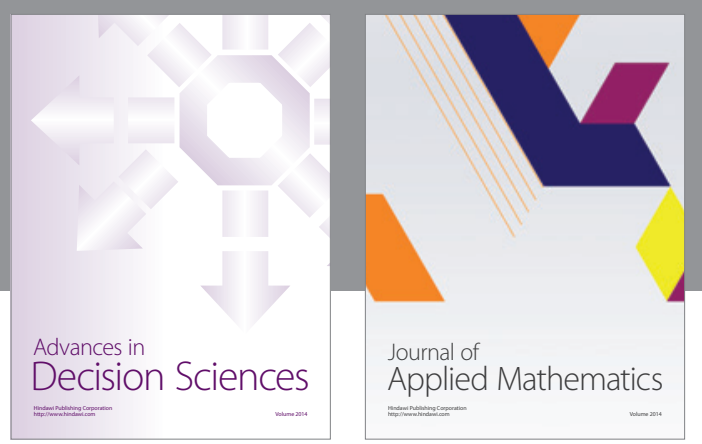

Algebra

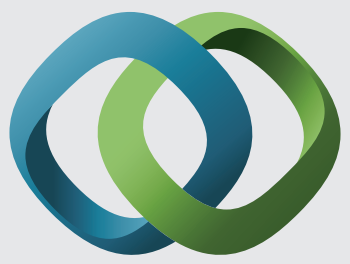

\section{Hindawi}

Submit your manuscripts at

https://www.hindawi.com
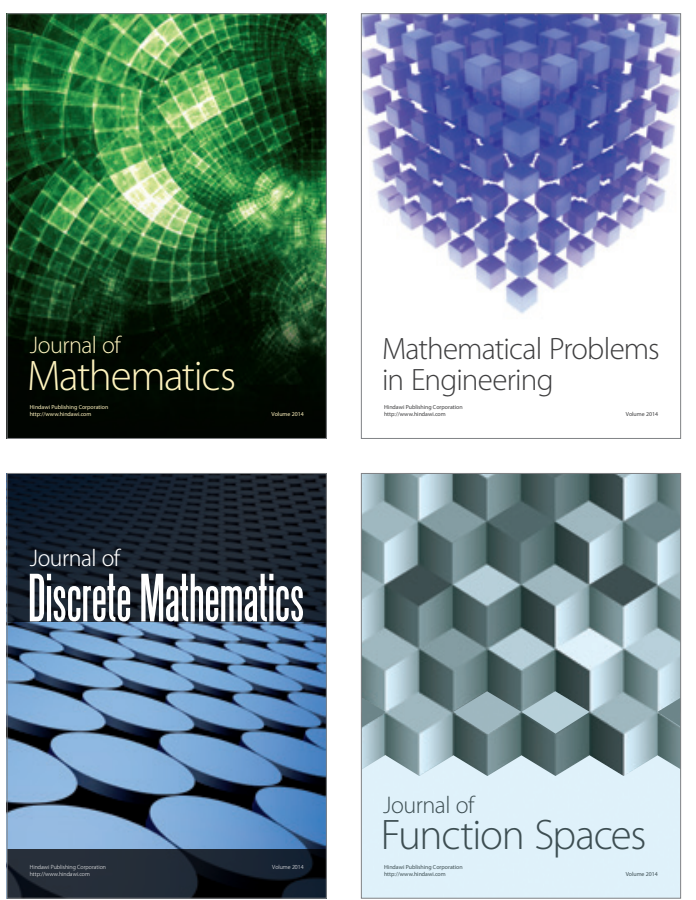

Mathematical Problems in Engineering
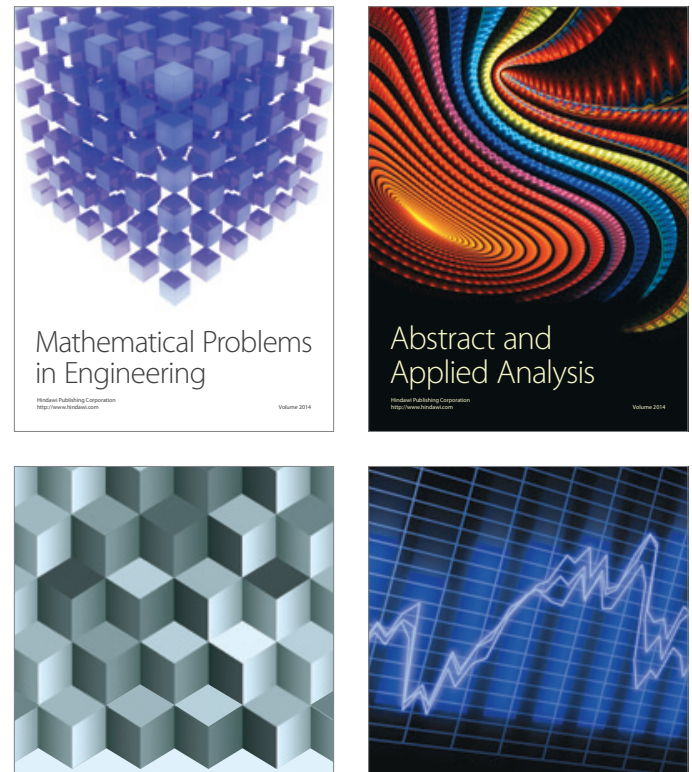

Journal of

Function Spaces

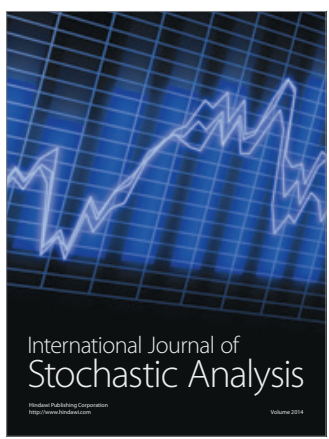

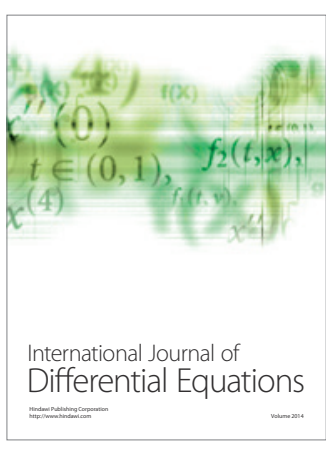
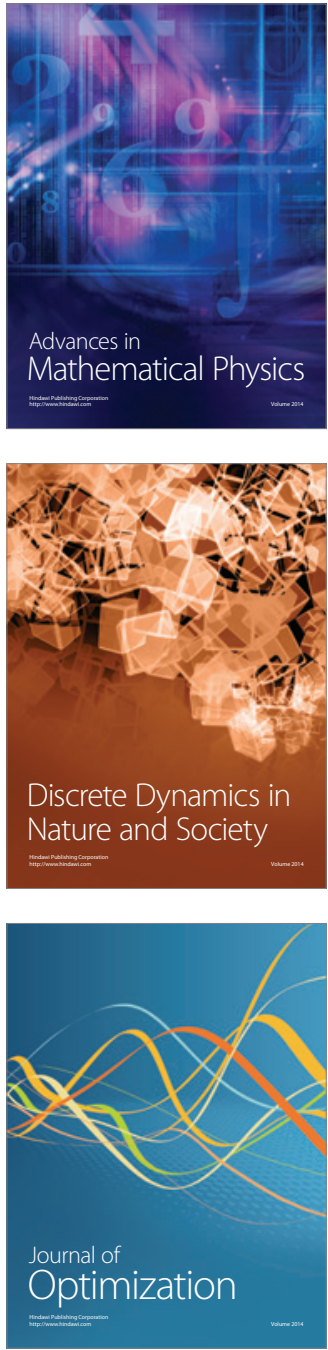